\title{
SMALL INTESTINAL BACTERIAL OVERGROWTH IS ASSOCIATED WITH INTESTINAL INFLAMMATION IN THE IRRITABLE BOWEL SYNDROME
}

\author{
LILIANA DAVID ${ }^{1}$, ALEXANDRU BABIN ${ }^{2}$, ALINA PICOS ${ }^{3}$, DAN LUCIAN \\ DUMITRASCU ${ }^{1}$
}

\author{
12nd Medical Department, Iuliu Hatieganu University of Medicine and Pharmacy, \\ Cluj-Napoca, Romania \\ ${ }^{2}$ Nicolae Testemitanu University of Medicine and Pharmacy, Kishinev, Moldova \\ ${ }^{3}$ Faculty of Dental Medicine, Iuliu Hatieganu University of Medicine and \\ Pharmacy, Cluj-Napoca, Romania
}

\begin{abstract}
Background and aim. Small intestinal bacterial overgrowth is encountered in bowel disorders, including irritable bowel symptoms. Low degrees of inflammation have been recently reported in the irritable bowel syndrome. We looked for the association between intestinal inflammation and small intestinal bacterial overgrowth in irritable bowel syndrome.

Methods. Small intestinal bacterial overgrowth was assessed by the $\mathrm{H} 2$ glucose breath test in 90 consecutive patients with irritable bowel syndrome. A check-up of the oral cavity was carried out before the breath testing. Further on, the patients were classified into two groups, positive and negative, at the breath test. Then they were tested for intestinal inflammation with a fecal test for calprotectin. We used a semiquantitative test for this study. Both groups were compared for the association of intestinal inflammation with small intestinal bacterial overgrowth.

Results. A number of 24/90 (26.7\%) patients with irritable bowel syndrome had small intestinal bacterial overgrowth. A positive test for intestinal inflammation was significantly more frequent in patients with irritable bowel syndrome and small intestinal bacterial overgrowth (chi $\left.i^{2}: p<0.05\right)$.

Conclusions. Small intestinal bacterial overgrowth is present in almost one quarter of patients with irritable bowel syndrome. It is significantly associated with intestinal inflammation.
\end{abstract}

Keywords: calprotectin, $\mathrm{H} 2$ breath test, irritable bowel syndrome, small intestinal bacterial overgrowth

\section{Introduction}

Small intestinal bacterial overgrowth (SIBO) is defined as the increased number of bacteria in the small bowel $[1,2]$. The cut-off value is considered maximum $10^{4}$ $\mathrm{CFU} / \mathrm{mL}$ and SIBO is defined largely as a concentration higher than $10^{5}[3]$.

SIBO was considered as a pathogenic factor in irritable bowel syndrome (IBS), because the prevalence of SIBO in IBS was considered high [4]. Later the prevalence

Manuscript received: 15.07.2014

Accepted: 30.07 .2014

Address for correspondence: ddumitrascu@umfcluj.ro value was reconsidered, but SIBO is still a factor to be assessed in patients with IBS $[5,6]$.

On the other hand, low levels of inflammation have been reported in IBS $[7,8]$, in contradiction with the first reports on the absence of any organic or biochemical changes in IBS [9].

In our hypothesis, the presence of bacteria in higher than normal concentration, may be related with the inflammation in the bowel. Therefore, the aim of this study was to check if SIBO may be associated with inflammation in IBS. 


\section{Methods}

\section{Protocol}

Consecutive patients with IBS were tested for SIBO. Consequently, they were tested for intestinal inflammation. We looked for the association between SIBO and intestinal luminal inflammation in IBS.

\section{Subjects}

Ninety consecutive subjects with IBS diagnosed according to Rome III criteria [9] were included in this study. They were 33 males and 57 females, aged between 19 to 72 years (median age 50 years). All patients agreed to participate and offered informed consent. Patients were recommended to undergo an oral examination, performed by the same experienced dentist (AP). This examination was provided in order to detect any potential local factors of bias.

\section{Assessment of SIBO}

We used the hydrogen breath test with glucose (GHBT). The test was performed after 12 hours fasting in each patient. After two measurements of baseline values for exhaled hydrogen, the patients were given $50 \mathrm{~g}$ glucose dissolved in $200 \mathrm{ml}$ water. Subsequently the breath samples were collected and analyzed for hydrogen every 10 minutes for 3 hours. SIBO was suspected if a peak was detected and if the exhaled peak value was superior to 10 parts per million over baseline values [10].

\section{Assessment of intestinal inflammation}

We used a semiquantitative fecal test, easy to use and cost-efficient [11]. Fecal calprotectin is considered a reliable surrogate marker for gut intraluminal inflammation [12]. It is routinely used for the assessment of inflammatory bowel disease (Morbus Crohn, ulcerative colitis) [13] but its levels may be slightly increased in IBS [14].

The assay used in this study was a semiquantittaive one, based on the immuno-chromatographic method, to detect the presence of calprotectin in the feces (CalDetect ${ }^{\circledR}$, SOFAR). The test can be performed in the same day, and the result is ready immediately, like in the fecal occult blood testing. This test indicates only negative or positive results. For the positive cases, the test gives one of these values: $\mathrm{T} 1$ if fecal calprotectin $<15 \mu \mathrm{g} / \mathrm{g}$ (suggesting minimal inflammation; $\mathrm{T} 2$ if fecal calprotectin $=15-60$ $\mu \mathrm{g} / \mathrm{g}$; T3 if fecal calprotectin $>60 \mu \mathrm{g} / \mathrm{g}$ [10]. We considered the value of $\mathrm{T} 2$ as corresponding to an inflammation in the bowel of IBS patients of low level. T3 represented severe inflammation.

\section{Statistics}

Descriptive statistics (mean \pm standard deviation) were used for parametric data. Continuous variables were compared using ANOVA or Mann-Whitney test depending on the normal or abnormal distribution of data. An error probability of $\mathrm{p}<0.05$ was considered statistically significant.

\section{Results}

The group of consecutive IBS patients included 33 males and 57 females. The age range varied between 19 to 72 years (median age 50 years).

Only 33 of the patients took benefit from the oral examination, the rest did not have time for appointment; 20 patients from 33 presented dental, lingual or gingival changes, but none able to influence the result of the examination. Therefore we did not stratify further the group of patients according to the dental health status.

Among the 90 subjects, we detected SIBO in 24 of them. These data indicated a prevalence of $26.7 \%$ of SIBO in patients with IBS. The main characteristics of the subjects are given in table I, according to their SIBO status: positive or negative.

Table I. Characteristics of the IBS patients with SIBO and without SIBO

\begin{tabular}{lccc}
\hline Characteristic & $\begin{array}{c}\text { SIBO } \\
\text { positive } \\
\mathbf{N = 2 4}\end{array}$ & $\begin{array}{c}\text { SIBO } \\
\text { negative } \\
\mathbf{N = 6 6}\end{array}$ & $\begin{array}{c}\text { Significance } \\
\text { of difference }\end{array}$ \\
\hline Age (mean+SD) & $44 \pm 10$ & $39 \pm 9$ & NS \\
\hline Gender M/F & $9 / 15$ & $24 / 42$ & NS \\
\hline $\begin{array}{l}\text { Level of education } \\
\text { Low/medium/high }\end{array}$ & $10 / 7 / 7$ & $31 / 15 / 20$ & \\
\hline IBS type: C/D/M & $8 / 4 / 12$ & $29 / 11 / 26$ & \\
\hline
\end{tabular}

Legend: IBS type: $\mathrm{C}=$ constipation; $\mathrm{D}=$ diarrhea; $\mathrm{M}=$ mixed

Both groups had similar characteristics. All subjects gave samples of feces for the estimation of calprotectin with a semiquantitative rapid fecal test. The results are displayed in table II.

Table II. Numbers of patients with the result of calprotectin positive, respectively negative GHBT

\begin{tabular}{lcc}
\hline & Calprotectin positive & Calprotectin negative \\
\hline SIBO positive & 16 & 8 \\
\hline SIBO negative & 13 & 53 \\
\hline
\end{tabular}

The groups were compared with the $\mathrm{chi}^{2}$ test. The calculation of the significance gave a $\mathrm{P}=2.5 \mathrm{E}-0.5$ and $\mathrm{p}<0.05$.

The test was semiquantitative, thus each patient could have a result from T1 to T3. All our negative subjects had the value $\mathrm{T} 1$, all positive subjects had the value $\mathrm{T} 2$, in accordance to previous data [12].

\section{Discussion}

This is to our knowledge the first study in our area 
looking for the association between SIBO and endoluminal inflammation in IBS. Our study showed that a positive test for intestinal inflammation was significantly more frequent in the IBS patients who also presented SIBO $\left(\mathrm{chi}^{2}: \mathrm{p}<0.05\right)$.

The prevalence of SIBO in IBS was $26.7 \%$ in this study, higher than in another Romanian medical center [6], but compatible with data to be reported from a Romanian multicenter study (Moraru et al, submitted).

Our data are consistent with other studies reporting low degree inflammation in IBS $[1,15]$ and contribute to the divergent values reported in different studies on the true prevalence of SIBO in IBS [16-18]. This study is not without limitations. The main one is the relatively reduced size of the sample. The subgroup of SIBO positive was especially small. However the data are consistent with those reported in similar studies and offer first data on SIBO in IBS in our area.

\section{Conclusions}

Small intestinal bacterial overgrowth is present in $26.7 \%$ of the patients with IBS. It is significantly associated to intestinal inflammation.

\section{References}

1. Gasbarrini A, Lauritano EC, Gabrielli M, Scarpellini E, Lupascu A, Ojetti V, et al. Small intestinal bacterial overgrowth: diagnosis and treatment. Dig Dis. 2007;25:237-240.

2. Bures J, Cyrany J, Kohoutova D, Förstl M, Rejchrt S, Kvetina $\mathrm{J}$, et al. Small intestinal bacterial overgrowth syndrome.World J Gastroenterol. 2010;16(24):2978-2990.

3. Khoshini R, Dai SC, Lezcano S, Pimentel M. A systematic review of diagnostic tests for small intestinal bacterial overgrowth. Dig Dis Sci. 2008;53:1443-1454.

4. Pimentel M, Chow EJ, Lin HC. Eradication of small intestinal bacterial overgrowth reduces symptoms of irritable bowel syndrome. Am J Gastroenterol. 2000;95:3503-3506.

5. Lupascu A, Gabrielli M, Lauritano EC, Scarpellini E, Santoliquido A, Cammarota G, et al. Hydrogen glucose breath test to detect small intestinal bacterial overgrowth: a prevalence casecontrol study in irritable bowel syndrome. Aliment Pharmacol Ther. 2005;22:1157-1160
6. Moraru IG, Portincasa P, Moraru AG, Diculescu M, Dumitraşcu DL.Small intestinal bacterial overgrowth produces symptoms in irritable bowel syndrome which are improved by rifaximin. A pilot study.Rom J Intern Med. 2013;51(3-4):143-147

7. Bashashati M, Rezaei N, Shafieyoun A, McKernan DP, Chang L, Ohman L, et al. Cytokine imbalance in irritable bowel syndrome: a systematic review and meta-analysis. Neurogastroenterol Motil. 2014;26(7):1036-1048.

8. Barbara G, Cremon C, Stanghellini V. Inflammatory bowel disease and irritable bowel syndrome: similarities and differences. Curr Opin Gastroenterol. 2014;30(4):352-358.

9. Longstreth GF, Thompson WG, Chey WD, Houghton LA, Mearin F, Spiller RC.Functional bowel disorders. Gastroenterology. 2006;130(5):1480-1491.

10. Ghoshal UC.How to interpret hydrogen breath tests.. J Neurogastroenterol Motil. 2011;17(3):312-317.

11. http://www.sofar.ro/sisteme-diagnosticare/cal-detect.html

12. Grad C, David L, Portincasa P, Dumitrascu DL. Diagnostic value of calprotectin in irritable bowel syndrome and in inflammatory bowel disease. Rom J Intern Med 2012;50:(1):3-6. 13. Lin JF, Chen JM, Zuo JH, Yu A, Xiao ZJ, Deng FH, et al. Metaanalysis: Fecal Calprotectin for Assessment of Inflammatory Bowel Disease Activity. Inflamm Bowel Dis. 2014 Jun 30. [Epub ahead of print], doi: 10.1097/MIB.0000000000000057.

14. Sydora MJ, Sydora BC, Fedorak RN.Validation of a pointof-care desk top device to quantitate fecal calprotectin and distinguish inflammatory bowel disease from irritable bowel syndrome. J Crohns Colitis. 2012;6(2):207-214.

15. Tibble JA, Sigthorsson G, Foster R, Forgacs I, Bjarnason I. Use of surrogate markers of inflammation and Rome criteria to distinguish organic from nonorganic intestinal disease. Gastroenterology. 2002;123(2):450-460.

16. Grover M, Kanazawa M, Palsson OS, Chitkara DK, Gangarosa LM, Drossman DA, Whitehead WE. Small intestinal bacterial overgrowth in irritable bowel syndrome: association with colon motility, bowel symptoms, and psychological distress. Neurogastroenterol Motil. 2008;20:998-1008.

17. Khoshini R, Dai SC, Lezcano S, Pimentel M. A systematic review of diagnostic tests for small intestinal bacterial overgrowth. Dig Dis Sci. 2008;53:1443-1454.

18. Ford AC, Spiegel BM, Talley NJ, Moayyedi P. Small intestinal bacterial overgrowth in irritable bowel syndrome: systematic review and meta-analysis. Clin Gastroenterol Hepatol. 2009;7:1279-1286. 